\title{
Virulência de estirpes (biovar 1 e 2T) de Ralstonia solanaceraum a Eucalyptus spp.
}

\author{
Virulence of Ralstonia solanacearum strains (biovar 1 and 2T) to Eucalyptus spp.
}

Eder Marques $^{\mathrm{I}^{*}}$ Carlos Hidemi Uesugi $^{\mathrm{I}}$ Luiz Eduardo Bassay Blum ${ }^{\mathrm{I}}$

\section{RESUMO}

A murcha bacteriana do eucalipto (Raça 3 biovar 2T de Ralstonia solanacearum) foi descrita em 2009 em campo com o híbrido de eucalipto urograndis. $O$ objetivo deste trabalho foi avaliar a virulência de duas estirpes de $\boldsymbol{R}$. solanacearum a dezessete espécies de Eucalyptus, através do teste de microbiolização de sementes. A análise estatística dentre espécies mostrou que a virulência variou entre as estirpes estudadas. A virulência da R3bv2T foi significativamente maior em: urograndis, E. urophylla, E. grandis $x$ E. camaldulensis, $\boldsymbol{E}$. grandis, E. microcorys, E. deanei e E. phaeotricha; e maior para R1bv1 somente na espécie $\boldsymbol{E}$. pellita. Entre espécies de eucalipto, observou-se maior suscetibilidade em "urograndis", $\boldsymbol{E}$. grandis e E. paniculata para R3bv2T; e em E. cloeziana, E. paniculata, $\boldsymbol{E}$. botryoides, $\boldsymbol{E}$. pellita, $\boldsymbol{E}$. propinqua e $\boldsymbol{E}$. resinifera devido a R1bv1.

Palavras-chave: murcha bacteriana, microbiolização de sementes, suscetibilidade.

\section{ABSTRACT}

The bacterial wilt of Eucalyptus (Ralstonia solanacearum Race 3 biovar 2T) was reported in field of Eucalyptus hybrid urograndis. The objective of this research was to evaluate the virulence of two R. solanacearum strains to 17 Eucalyptus species, using the seed microbiolization method for pathogen inoculation. The results of the statistical analyses showed that virulence varied between the two $\boldsymbol{R}$. solanacearum strains. The R3bv2T virulence was higher than the one in R1bv1 in the following Eucalyptus species: urograndis, E. urophylla, E. grandis $x$ E. camaldulensis, E. grandis, E. microcorys, E. deanei, and E. phaeotricha. The virulence of the R1bv1 strain was higher only in E. pellita. Among species of Eucalyptus the following ones were more susceptibles: to $R 3 b v 2 T$ strain - urograndis, $\boldsymbol{E}$. grandis and $\boldsymbol{E}$. paniculata, and to R1bv1 strain - E. cloeziana, E. paniculata, E. botryoides, E. pellita, E. propinqua and E. resinifera.

Key words: bacterial wilt, seed microbiolization, susceptibility.

\section{INTRODUÇÃO}

Ralstonia solanacearum (SMITH, 1986) (YABUUCHI, 1995) é uma bactéria que afeta mais de 200 espécies de plantas distribuídas em 50 famílias botânicas (HAYWARD, 1994). Sua gama de hospedeiras ainda não é bem definida, pois mudanças na sistemática agrícola e no comércio global de mudas e sementes têm levado ao aparecimento de novas hospedeiras para isolados evasivos desse patógeno (TSUCHIYA, 2004). Um exemplo disso foi o ocorrido em 2009, quando a Raça 3 biovar $2 \mathrm{~T}$ (R3bv2T) da bactéria foi relatada pela primeira vez, infectando um cultivo inicial do híbrido "urograndis" (Eucalyptus urophylla x Eucalyptus grandis), no município de Alexânia - Goiás (MARQUES et al., 2012). No Brasil, em infecção natural, a murcha bacteriana ocorre devido a biovar $1 \mathrm{e}$, nos demais países, pela biovar 3. Essa doença já foi responsável por elevadas perdas em viveiros clonais de eucalipto dos Estados da Bahia, Espírito Santo, Maranhão, Minas Gerais e Pará, em decorrência do descarte de mudas contaminadas com o patógeno (ALFENAS et al., 2006).

A avaliação da reação de procedências resistentes de eucalipto a estirpes de $\boldsymbol{R}$. solanacearum é considerada a abordagem mais efetiva para a redução na severidade da doença (RAN et al., 2005), especialmente na bacteriose do eucalipto, em que a produção de mudas é basicamente clonal e altamente favorável à multiplicação e transmissão da bactéria

\footnotetext{
IDepartamento de Fitopatologia, Instituto de Ciências Biológicas (IB), Universidade de Brasília (UnB), 70910-900, Brasília, DF, Brasil. E-mail: eder.marques.08@gmail.com.*Autor para correspondência. 
(ALFENAS et al., 2006). Entretanto, ainda não existe um método padrão para avaliar a doença em eucalipto e, nos métodos existentes, raramente há reprodução dos sintomas, provavelmente devido à natureza lenhosa da planta (MAFIA, 2006). Técnicas como, inundação do solo com suspensão bacteriana, ferimentos com picada de agulha e microbiolização de sementes têm sido utilizados para avaliação em estudos de resistência (GAN et al., 2004), virulência (DIANESE \& DRISTIG, 1993; MAFIA, 2006) e patogenicidade da bactéria (RODRIGUES, 2010). Porém, estudos de avaliação da virulência de estirpes são escassos, assim como os de resistência genética à murcha bacteriana em eucalipto.

Virulência é um termo utilizado para expressar diferentes graus de patogenicidade de um patógeno, que pode causar maior ou menor dano ao hospedeiro em um determinado tempo (BLUM, 2006). DIANESE et al. (1990) avaliaram a virulência de nove isolados de $\boldsymbol{R}$. solanacearum Raça 1 biovar 1 (R1bv1) a eucalipto, tomate, pimentão e berinjela, sendo que apenas um deles foi mais virulento nas quatro espécies testadas. Posteriormente, DIANESE \& DRISTIG (1993) avaliaram a virulência dos mesmos isolados da bactéria através de diferentes formas de inoculação em eucalipto. O método de inoculação de $10 \mu \mathrm{L}$ de suspensão em ferimentos nas axilas foliares foi o mais eficiente para indução de níveis satisfatórios de murcha.
Tendo em vista os poucos estudos da virulência de estirpes de $\boldsymbol{R}$. solanacearum, da ausência de métodos padrões para estudos de suscetibilidade do hospedeiro e do relato de uma nova biovar infectando eucalipto, foi objetivo deste trabalho: avaliar a virulência, pelo método de microbiolização de sementes, de duas estirpes de $\boldsymbol{R}$. solanacearum a dezessete espécies e híbridos de Eucalyptus.

\section{MATERIAL E MÉTODOS}

Os experimentos foram realizados no Laboratório de Bacteriologia Vegetal do Departamento de Fitopatologia do Instituto de Ciências Biológicas - Universidade de Brasília. Para avaliação da virulência, foram utilizadas duas estirpes de Ralstonia solanacearum: UnB 1359 - Raça 3 biovar 2T - oriunda do híbrido "urograndis", coletada em Alexânia - GO (MARQUES et al., 2012) e UnB 575 - Raça 1 biovar 1 - oriunda de $\boldsymbol{E}$. urophylla, coletada em Monte Dourado - PA (DIANESE \& DRISTIG, 1993), além de dezessete espécies/cruzamentos de eucalipto (Tabela 1), parte doada pelo IPEF (Instituto de Pesquisas e Estudos Florestais, Piracicaba - SP) e parte comprada do mesmo Instituto. As estirpes bacterianas foram obtidas da Coleção de Bactérias Fitopatogênicas, do Departamento de Fitopatologia, da Universidade de Brasília. A recuperação foi feita

Tabela 1 - Descrição das espécies e híbridos de Eucalyptus utilizados nos testes de virulência de Ralstonia solanacearum.

\begin{tabular}{|c|c|c|c|c|}
\hline Espécies/Cruzamentos & Procedência ${ }^{1}$ & $\mathrm{Grau}^{2}$ & $\begin{array}{l}\text { Viabilidade das } \\
\text { sementes }(\%)\end{array}$ & Safra \\
\hline E. urophylla & Anhembi - SP & APS-MS (F1) ${ }^{3}$ & 81 & 2009 \\
\hline E. urophylla $\times$ E. grandis & Anhembi - SP & PMS (F3) & $\mathrm{NF}^{5}$ & 2010 \\
\hline E. grandis $\times$ E. camaldulensis & Anhembi - SP & APS-MS (F3) & NF & 2011 \\
\hline E. cloeziana & Anhembi - SP & APS-MS (F1) & 86 & 2008 \\
\hline E. grandis & Itatinga - SP & APS-MS (F2) & 97 & 2009 \\
\hline E. microcorys & Itatinga - SP & APS-MS (F2) & 68 & 2007 \\
\hline E. paniculata & Itatinga - SP & APS-MS (F1) & NF & 2011 \\
\hline E. exserta & Itatinga - SP & APS-MS (F2) & 70 & 2002 \\
\hline E. acmenoides & Itatinga - SP & APS-MS (F2) & NF & 2007 \\
\hline E. botryoides & Anhembi - SP & APS-MS (F1) & 81 & 1991 \\
\hline E. deanei & Anhembi - SP & APS-MS (F2) & NF & 2007 \\
\hline E. pellita & Anhembi - SP & APS-MS (F1) & 95 & 2010 \\
\hline E. phaeotricha & Anhembi - SP & APS-MS (F1) & 72 & 1990 \\
\hline E. pilularis & Anhembi - SP & APS-MS (F1) & NF & 2008 \\
\hline E. propinqua & Anhembi - SP & APS-MS (F1) & NF & 1991 \\
\hline E. resinifera & Anhembi - SP & APS-MS (F1) & 93 & 1995 \\
\hline E. robusta & Itatinga - SP & APS-MS (F2) & 91 & 2009 \\
\hline
\end{tabular}

${ }^{1}$ Dados do fornecedor/produtor; ${ }^{2}$ Grau de Melhoramento; ${ }^{3}$ Área de Produção de Sementes e Fn (n=1 a 5); Geração de Melhoramento; ${ }^{4}$ Pomar de Sementes por Mudas; ${ }^{5}$ Dado não fornecido. 
diretamente dos tubos com água destilada esterilizada contendo as culturas preservadas e após as repicagens em meio KELMAN (1954), foram utilizadas as colônias virulentas.

A metodologia utilizada foi adaptada de RODRIGUES (2010), a qual o autor utilizou para avaliar a patogenicidade de linhagens de $\boldsymbol{R}$. solanaceraum, realizada da seguinte forma: desinfestação superficial das sementes de eucalipto por imersão em álcool 70\% (30s), seguida da imersão em solução de hipoclorito de sódio $1 \%$ (3min) e lavagem em água destilada estéril, por duas vezes consecutivas. A seguir, as sementes foram imersas nas respectivas suspensões bacterianas na concentração de aproximadamente $10^{9} \mathrm{UFC} / \mathrm{mL}$ (Escala 7 de McFarland), por $24 \mathrm{~h}$ a $28^{\circ} \mathrm{C}$ e agitadas a $150 \mathrm{rpm}$ em incubador rotativo, com exceção das sementes testemunhas, que foram mantidas nas mesmas condições, porém em água destilada e esterilizada. Após esse período, as sementes foram depositadas individualmente em tubos tipo "Falcon" (50mL), contendo $10 \mathrm{~mL}$ de meio ágar-água $(0,85 \%)$. Os tubos foram colocados em estantes, mantidos a temperatura $\left(24 \sim 25^{\circ} \mathrm{C}\right)$ e luz ambientes.

O experimento foi em blocos ao acaso com 5 repetições, com 4 sementes cada em um esquema fatorial (17x2). Após 30 dias, observou-se o número de sementes não germinadas ou plântulas com crescimento afetado pela ação da bactéria. Das médias dos tratamentos, foi subtraído o número de sementes não germinadas da testemunha antes da análise estatística, retirando, assim, o efeito das sementes não germinadas por outros motivos (MOREIRA \& PAUSA, 2012), que não a ação da fitobactéria. Após a análise de variância, aplicou-se o teste de Scott-Knott $(\mathrm{P} \leq 0,05)$ para comparação e separação das médias.

\section{RESULTADOS E DISCUSSÃO}

Os estudos relacionados à murcha bacteriana do eucalipto têm sido realizados em espécies puras, procedências, clones e híbridos (GAN et al., 2004). Como já mencionado, diferentes métodos de inoculação foram desenvolvidos e não existem protocolos definidos (MAFIA, 2006). Neste trabalho, foi estudada a virulência de uma estirpe da Raça 1 biovar 1 em comparação com uma da Raça 3 biovar 2T, ambas isoladas de eucalipto, utilizando a microbiolização de sementes. Essa técnica é utilizada principalmente quando o objetivo é o biocontrole de patógenos no solo ou na promoção de crescimento de plantas (LUZ, 1993). Como nos métodos existentes raramente há reprodução dos sintomas da doença, provavelmente devido à natureza lenhosa do eucalipto (MAFIA, 2006), a microbiolização pode ser considerada como um método de infecção natural da planta em estágio inicial de germinação ou crescimento, útil para avaliação da murcha do eucalipto ou da virulência de estirpes bacterianas.

A análise com essa técnica mostrou que as sementes foram afetadas em sua germinação ou tiveram seu crescimento reduzido (Figura 1). As sementes testemunhas mostraram variação na germinação, algumas tiveram baixa germinação, talvez pelo baixo vigor ou por estar fora do prazo de validade, quando analisado o boletim fornecido pelo Instituto de Pesquisa e Estudos Florestais, que acompanha o termo de conformidade de sementes (Figura 1). Segundo FERRARI (2003), sementes de eucalipto, por seu tamanho, apresentam-se, muitas vezes, com uma quantidade alta de material inerte misturado, principalmente sementes não fecundadas, reduzindo o número de sementes viáveis por quilograma. Dessa forma, optou-se por retirar o efeito das sementes testemunhas não germinadas (MOREIRA \& PAUSA, 2012).

$\mathrm{O}$ experimento em fatorial permitiu comparar tanto o efeito das duas estirpes, ou seja, a virulência, quanto a interação entre espécies de eucalipto e estirpes bacterianas, a suscetibilidade dessas espécies. Os resultados mostraram que a virulência, dentre as espécies de eucalipto, foi maior devido a R3bv2T, quando comparada a R1bv1 em E. urophylla, E. urophylla $\times$ E. grandis, E. grandis $\mathrm{X} \boldsymbol{E}$. camaldulensis, E. grandis, E. microcorys, $\boldsymbol{E}$. deanei e $\boldsymbol{E}$. phaeotricha. Somente na espécie $\boldsymbol{E}$. pellita a estirpe da R1bv1 foi mais virulenta que a R3bv2T. Nas demais espécies, a suscetibilidade das espécies foi estatisticamente semelhante para ambas às estirpes bacterianas avaliadas (Tabela 2, letras maiúsculas nas linhas).

Os poucos estudos descritos na literatura associados à virulência de estirpes de R. solanacearum utilizam diferentes métodos de inoculação ou avaliação, tais como inoculação por picada de agulha ou inoculação de suspensão bacteriana. DIANESE et al. (1990) observaram que estirpes isoladas de eucalipto mostraram diferenças quanto à virulência em tomate, pimentão e batata, sendo a estirpe UnB 577 (R1bv1, de eucalipto) o que exibiu maior virulência em todas as plantas testadas. Mais tarde, DIANESE \& DRISTIG (1993) observaram que estirpes das biovares, originárias de outras hospedeiras podem se mostrar mais virulentas a eucalipto do que suas próprias estirpes. Nesse caso, as biovares 1, 2 e 3, pertencentes a outras plantas 


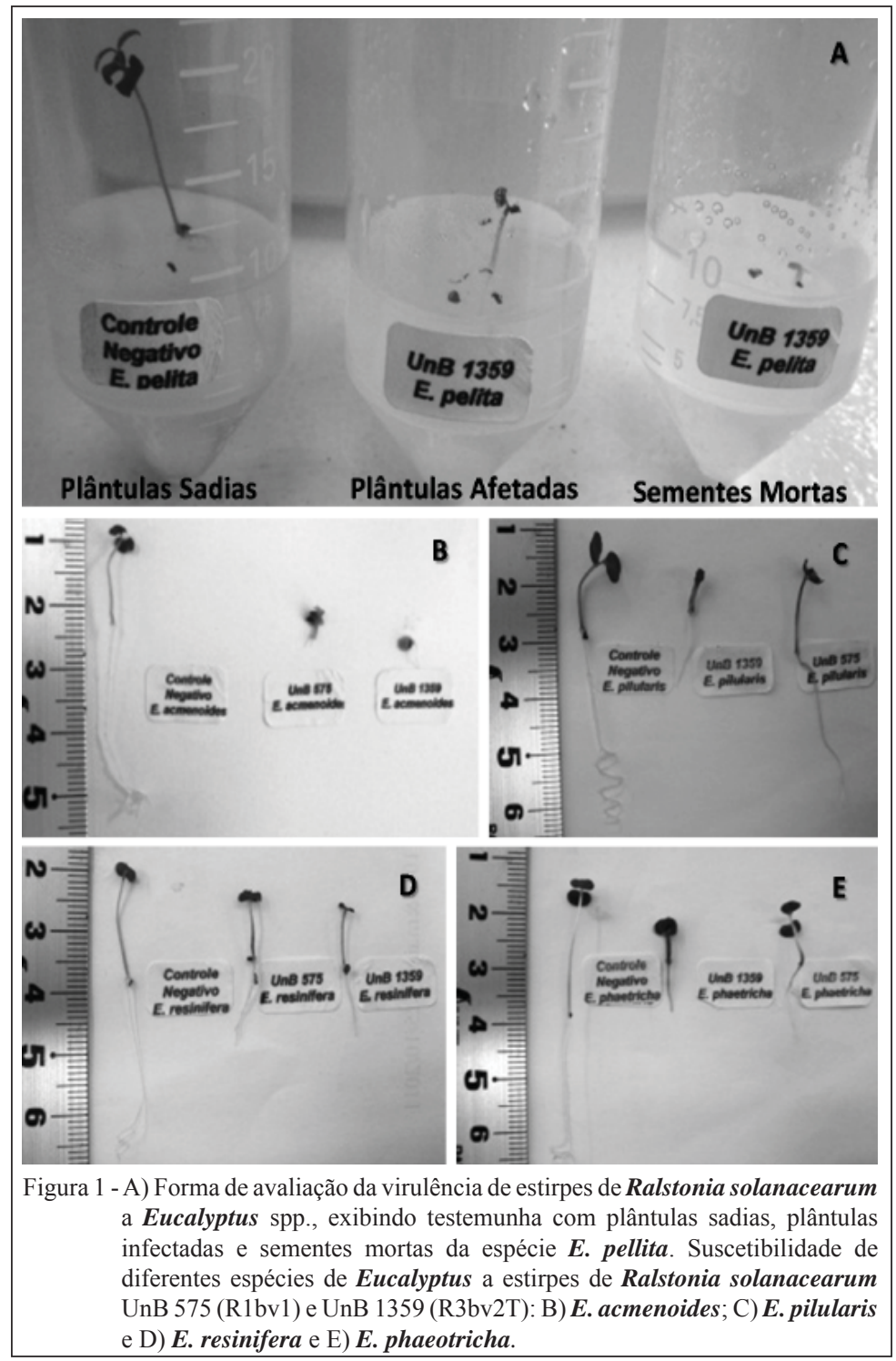

foram mais virulentas a $\boldsymbol{E}$. grandis do que a estirpe UnB 575 biovar 1 de eucalipto. Por outro lado, entre as estirpes de eucalipto, a estirpe UnB 575 foi a mais virulenta. RODRIGUES (2010), avaliando a patogenicidade de linhagens de $\boldsymbol{R}$. solanaceraum, através de microbiolização in vitro de sementes de eucalipto, também relatou que estirpes das biovares 1,2 e 3 de diferentes hospedeiras infectaram plantas de $\boldsymbol{E}$. grandis ou afetaram seu crescimento. Observou também que duas linhagens da R3bv2 isoladas de batata e gerânio, respectivamente, apresentaram agressividade maior do que as linhagens da raça 1, quando inoculadas em tomateiro.

Considerando a suscetibilidade entre as espécies de eucalipto, formaram-se quatro grupos em reação a $\mathrm{R} 3 \mathrm{bv} 2 \mathrm{~T}$, o primeiro inclui as mais suscetíveis, englobando o híbrido urograndis e as espécies $\boldsymbol{E}$. grandis e $\boldsymbol{E}$. paniculata, e o último com as espécies com menor mortalidade, ou seja, as menos suscetíveis: $\boldsymbol{E}$. exserta e $\boldsymbol{E}$. pilularis. Por outro lado, em reação a R1bv1, formaram-se três grupos, sendo as espécies mais suscetíveis: $\boldsymbol{E}$. cloeziana, E. paniculata, E. botryoides, E. pellita, $\boldsymbol{E}$. propinqua e $\boldsymbol{E}$. resinifera e menos suscetíveis: os híbrido urograndis e $\boldsymbol{E}$. grandis $\times$ E. camaldulensis e as espécies E. urophylla, E. grandis, E. exserta, E. deanei, E. phaeotricha, E. pilullaris e E. robusta (Tabela 2, letras minúsculas nas colunas).

Os relatos, para as biovares 1 e 3 no Brasil e no mundo, dizem que E. exserta (WU \& LIANG, 
Tabela 2 - Avaliação da virulência de estirpes de Ralstonia solanacearum a espécies e híbridos de Eucalyptus, mostrando as médias nos tratamentos de sementes mortas ou plântulas subdesenvolvidas.

\begin{tabular}{lll}
\hline & & \\
Espécies/Cruzamentos & $\mathrm{R} 3 \mathrm{bv} 2 \mathrm{~T}$ & $\mathrm{R} 1 \mathrm{bv} 1$ \\
& & \\
\hline E. urophylla & $3,15 \mathrm{bA} *$ & $0,45 \mathrm{cB}$ \\
E. urophylla x E. grandis & $4,00 \mathrm{aA}$ & $0,60 \mathrm{cB}$ \\
E. grandis x E. camaldulensis & $3,20 \mathrm{bA}$ & $0,20 \mathrm{cB}$ \\
E. cloeziana & $3,40 \mathrm{bA}$ & $3,40 \mathrm{aA}$ \\
E. grandis & $4,00 \mathrm{aA}$ & $0,00 \mathrm{cB}$ \\
E. microcorys & $3,20 \mathrm{bA}$ & $1,84 \mathrm{bB}$ \\
E. paniculata & $4,00 \mathrm{aA}$ & $3,40 \mathrm{aA}$ \\
E. exserta & $0,80 \mathrm{dA}$ & $0,60 \mathrm{cA}$ \\
E. acmenoides & $1,80 \mathrm{cA}$ & $2,00 \mathrm{bA}$ \\
E. botryoides & $3,20 \mathrm{bA}$ & $3,20 \mathrm{aA}$ \\
E. deanei & $2,00 \mathrm{cA}$ & $0,80 \mathrm{cB}$ \\
E. pellita & $2,00 \mathrm{cB}$ & $3,04 \mathrm{aA}$ \\
E. phaeotricha & $1,44 \mathrm{cA}$ & $0,00 \mathrm{cB}$ \\
E. pilularis & $0,00 \mathrm{dA}$ & $0,00 \mathrm{cA}$ \\
E. propinqua & $2,80 \mathrm{bA}$ & $3,20 \mathrm{aA}$ \\
E. resinifera & $3,20 \mathrm{bA}$ & $3,04 \mathrm{aA}$ \\
E. robusta & $1,24 \mathrm{cA}$ & $0,48 \mathrm{cA}$ \\
\hline
\end{tabular}

*Médias seguidas pela mesma letra minúscula nas colunas (suscetibilidade entre espécies de eucalipto) e maiúscula nas linhas (virulência entre estirpes bacterianas na mesma espécie de Eucalyptus) não diferem estatisticamente pelo teste de ScottKnott $(\mathrm{P} \leq 0,05)$.

1988), E. cloeziana, E. resinifera (DIANESE \& DRISTIG, 1993), E. pellita, E. robusta, E. pilularis (DIANESE \& DRISTIG, 1993; DIANESE et al., 1990; WU \& LIANG, 1988), E. deanei (DIANESE \& DRISTIG, 1993; DIANESE et al., 1990), E. grandis x E. camaldulensis (COUTINHO et al., 2000) são tolerantes ou resistentes a $\boldsymbol{R}$. solanacearum. Já E. pilularis e urograndis (SHI et al., 2000; LI \& WU,1996; DIANESE et al., 1990), assim como E. urophylla, E. grandis (WU \& LIANG, 1988; DIANESE et al., 1990; DIANESE \& DRISTIG, 1993; LI \& WU, 1996; MAFIA, 2006) e E. microcorys (DIANESE \& DRISTIG, 1993), são consideradas suscetíveis à fitobactéria.

No Brasil, as espécies mais plantadas são a E. grandis (55\%), E. saligna (17\%), E. urophylla (9\%), E. viminalis (2\%), híbridos de E. grandis $\times$ E. urophylla (11\%) e outras espécies (6\%) (REMADE, 2001). Dessa forma, as espécies $\boldsymbol{E}$. exserta e $\boldsymbol{E}$. pilularis, consideradas aqui como menos suscetíveis a $\boldsymbol{R}$. solanacearum podem ser estudadas em programas de manejo da doença. Todavia, estudos in vivo devem ser conduzidos para confirmação dos resultados aqui reportados.

\section{CONCLUSÃO}

A metodologia utilizando o teste de microbiolização de sementes foi útil e permitiu verificar que a virulência das estirpes de $\boldsymbol{R}$. solanacearum da Raça 3 biovar $2 \mathrm{~T}$ foi maior que as da Raça 1 biovar 1, nas espécies de eucalipto avaliadas.

\section{AGRADECIMENTOS}

Os autores agradecem ao Conselho Nacional de Desenvolvimento Científico e Tecnológico (CNPq), pela concessão de bolsa no curso de Doutorado do primeiro autor (Universidade de Brasília, 2012), e ao IPEF - Instituto de Pesquisas e Estudos Florestais (IPEF), por doar parte das sementes utilizadas neste estudo.

\section{REFERÊNCIAS}

ALFENAS, A.C. et al. Ralstonia solanacearum em viveiros clonais de eucalipto no Brasil. Fitopatologia Brasileira, v.31, n.4, p.357-366, 2006. Disponível em: <http://www.scielo.br/ scielo.php?pid=S0100-41582006000400005\&script $=$ sci_arttext $>$. Acesso em: 11 jan. 2011. doi: 10.1590/S0100-41582006000400005.

BLUM, L.E.B. Fitopatologia: o estudo das doenças de plantas. Brasília: Otimismo, 2006. 265p.

COUTINHO, T.A. et al. First report of bacterial wilt caused by Ralstonia solanacearum on eucalypts in South Africa. Forest Pathology, v.30, n.4, p.205-210, 2000

DIANESE, J.C.; DRISTIG, M.C.G. Screening Eucalyptus selections for resistance to bacterial wilt caused by Pseudomonas solanacearum. In: BACTERIAL WILT PROCEEDINGS OF AN INTERNATIONAL CONFERENCE ACIAR, 45, 1993, Kaohsiung, Taiwan. Proceedings... Taiwan, 1993. p.206-210. Acesso em: 5 fev. 2010. Disponível em: <http://aciar.gov.au/files/node/2182/ bacterial_wilt_part_6_13511.pdf $>$. Acesso em: 05 jan. 2012.

DIANESE, J.C. et al. Susceptibility to wilt associated with Pseudomonas solanacearum among six species of Eucalyptus growing in equatorial Brazil. Australasian Plant Pathology, v.19, n.3, p.71-76, 1990. Disponível em: <http://www.publish. csiro.au/?act=view_file\&file_id=APP9900071.pdf $>$. Acesso em: 17 jul. 2010.

FERRARI, M.P. Cultivo de eucalipto - Produção de mudas. Colombo: Embrapa Florestas, 2003. Disponível em: <http:// sistemasdeproducao.cnptia.embrapa.br/FontesHTML/Eucalipto/ CultivodoEucalipto/03 01 sementes.htm>. Online. Acesso em: 25 abr. 2011.

GAN, S. etal. Genetic analysis of growth and susceptibility to bacterial wilt (Ralstonia solanacearum) in Eucalyptus by interspecific factorial crossing. Silvae Genetica, v.53, n.5-6, p.254-258, 2004. Disponível em: <http:/www.silvaegenetica.com/fileadmin/content/ dokument/archiv/silvaegenetica/53 2004/53-5-6-254.pdf $>$. Acesso em: 18 jan. 2010. 
HAYWARD, A.C. The hosts of Pseudomonas solanacearum. In: HAYWARD A.C.; HARTMAN G.L. Bacterial wilt: the disease and its causative agent, Pseudomonas solanacearum. Willingford: CAB International, 1994. p.25-34.

KELMAN, A. The relationship of pathogenicity in Pseudomonas solanacearum to colony appearance on a tetrazolium medium. Phytopathology, v.44, p.693-695, 1954. Disponível em: <http:// garfield.library.upenn.edu/classics1983/A1983QM45400001. pdf $>$. Acesso em: 20 jan. 2009.

LI, H.; WU, X.Y. The current status, causes and control of forest diseases in Haiman province. Tropical Forestry, v.24, p.101-103, 1996.

LUZ, W.C. Microbiolização de sementes para o controle de doenças de plantas. Revisão Anual de Patologia de Plantas, v.1, p.33-77, 1993.

MAFIA, R.G. Sintomatologia, etiologia e controle da murcha bacteriana do eucalipto. 2006. 96f. Tese (Doutorado em Fitopatologia) - Programa de Pós-graduação em Fitopatologia, Universidade Federal de Viçosa, MG.

MARQUES, E. et al. Characterization of isolates of Ralstonia solanacearum biovar 2, pathogenic to Eucalyptus urograndis hybrids. Tropical Plant Pathology, v.37, p.399-408, 2012. Disponível em: <http://www.scielo.br/pdf/tpp/v37n6/a04v37n6. pdf $>$. Acesso em: 20 jan. 2013. http://dx.doi.org/10.1590/S198256762012000600004 .

MOREIRA, B.; PAUSAS, J.G. Tanned or burned: the role of fire in shaping physical seed dormancy. PLoS ONE, v.7, p.1-8, 2012. Disponível em: <http://www.plosone.org/article/ info $\% 3$ Adoi $\% 2 F 10.1371 \% 2 F j o u r n a l . p o n e .0051523>$. Acesso em: 12. abr. 2012.

RAN, L.X. et al. Suppression of bacterial wilt in Eucalytpus urophylla by fluorescent Pseudomonas spp. in China. Biological Control, v.32, n.1, p.111-120, 2005. Disponível em: <http://web.
science.uu.nl/pmi/publications/PDF/2005/BiolContrl-Ran-2005. pdf $>$. Acesso em: 12 mar. 2011.

REMADE. O eucalipto e suas origens. Disponível em: $<\mathrm{http}: / /$ www.remade.com.br/br/revistadamadeira_materia.php? num $=2$ $0 \&$ subject $=$ Origens \& title $=\mathrm{O} \% 20$ Eucalipto $\% 20 \mathrm{e} \% 20$ Suas $\% 20$ Origens $>$. Online. Acesso em: 15 dez. 2012.

RODRIGUES, L.M.R. Avaliação da agressividade e caracterização genética de linhagens de Ralstonia solanacearum isoladas de diferentes plantas hospedeiras. 2010. 79f. Dissertação (Mestrado em Agronomia) - Faculdade de Ciências Agronômicas, Universidade Estadual Paulista, SP.

SHI, Z.M. et al. Studies on selection of Eucalyptus for resistance to bacterial wilt and resistance stability. Guangxi Forestry Science, v.29, p.1-6, 2000

SMITH, E.F. A bacterial disease of tomato, eggplant and Irish potato (Bacillus solanacearum sp. nov.). US: Department of Agriculture Division of Vegetable Physiology and Pathology, 1986. p.21-28. (Bulletin n.12)

TSUCHIYA, K. Molecular biological studies of Ralstonia solanacearum and related plant pathogenic bacteria. Journal of General Plant Pathology, v.70, p.385-387, 2004.Disponível em: $<$ http://link.springer.com/article/10.1007\%2Fs10327-004-01463? LI=true >. Acesso em: 15 fev. 2011. doi: 10.1007/s10327-0040146-3.

WU, Q.P.; LIANG, Z.C. Selection of species and provenance of Eucalyptus for resistances to bacterial wilt. Journal of South China Agricultural University, v.9, n.4, p.41-45, 1988.

YABUUCHI, E. et al. Transfer of two Burkholderia 42 and an Alcaligenes species to Ralstonia gen. nov.: proposal of Ralstonia pickettii (Ralston, Palleroni and Douderoff 1973) comb. nov., Ralstonia solanacearum (Smith 1896) comb. nov. \& Ralstonia eutropha (Davis 1969) comb. nov. Microbiology and Immunology, v.39, p.897-904, 1995. 